\title{
PENELITIAN KONVERSI KULIT DOMBA, KAMBING KROM BASAH MENJADI KULIT JAKET, GLASE DITINJAU DARI PARAMETER PROSESNYA SEBAGAI PRODUK PERDAGANGAN
}

Oleh : Soetjipto, Soekarjono, Sanyoto, Susilowati, Endang Titik Widyaningsih, Rutini, Isrofiah

\begin{abstract}
The object of this research is to determine mutual converted value between unfinished leather to finished leather as commercial commodity. The raw materials are wet chrome tanned goatskins which are converted into jacket leather and chrome tanned goatskins into glace leather. Weight, wide, thickness is measured during this process, and the last is carried out in accordance with Indonesia Industrial Standard, for each step of the process. The sample taken in accordance with ISO. 25881973 is $n=0,5 \sqrt{ } \mathrm{N}$, where $\mathrm{N}$ is the number of cattle slaughtered. The sheeps taken were 148 sheets (197 sheets available) and the goats taken were 130 sheets (195 sheets available). The conclusion of this research are the conversion value of some sheepskins and goatskins from chrome tanned, sheepskins into glace and goatskins into jacket.
\end{abstract}

\section{INTISARI}

Penelitian ini bertujuan untuk menentukan nilai konversi hubungan timbal balik antara tahap sebelum dan sesudah pengolahan kulit sesuai produk perdagangan. Dimulai dari kulit krom basah, menjadi kulit jaket untuk kulit domba dan menjadi kulit glase untuk kulit kambing. Dilakukan pengukuran terhadap berat, luas dan tebal. Cara pengambilan sampel menurut ISO. 2588-1975. Jumlah sampel adalah $\mathrm{n}=0,5 \sqrt{\mathrm{N}}$, dimana $\mathrm{N}=$ jumlah ternak yang dipotong, sehingga sample untuk domba = 130 lembar diperoleh 195 lembar, untuk kulit kambing 148 lembar diperoleh 197 lembar. Dari pengolahan data dapat disimpulkan, beberapa harga konversi kulit domba dan kulit kambing dimulai dari kulit krom basah sampai kulit jaket dan kulit glase. 


\section{PENDAHULUAN}

\subsection{LATAR BELAKANG}

Saat ini telah ada buku-buku perkulitan yang menganalisa tentang konversi antara parameter proses, tetapi buku-buku tersebut menggambarkan produk- produk kulit di negara-negara tertentu yang kondisi kulitnya sangat berbeda dengan kulit yang ada di Indonesia. Oleh karena itu perlu adanya penelitian mengenai konversi kulit domba krom basah menjadi kulit jaket dan kulit krom basah domba menjadi kulit glase ditinjau dari parameter prosesnya sebagai produk perdagangan.

\subsection{TÚJUAN DAN SASARAN PENELITIAN}

\subsubsection{Tujuan Penelitian}

Untuk menentukan perbandingan nilai konversi dan hubungan timbal balik antara tahap sebelum dan sesudahnya dari tahap pengolahan kulit sebagai produk perdangan, dimulai dari kulit krom basah.

Untuk kulit domba krom basah menjadi kulit jaket.

Untuk kulit kambing krom basah menjadi kulit glase.

\subsubsection{Sasaran Penelitian}

Harga konversi dalam luas dan berat untuk kulit krom basah tidak diketam, kulit krom basah diketam, kulit kras serta kulit jaket dan kulit glase sebagai produk perdagangan.

\subsection{RENCANA PENELITIAN}

\subsubsection{Pengolahan Kulit}

Sebelum kulit domba dan kambing krom basah dikerjakan lebih lanjut, diadakan pengukuran :

a. 4 Luas kulit dalam kaki persegi

b. 4 Berat kulit dalam kilogram

c. Tebal kulit dalam milimeter.

Pentahapan pengolahan kulit :

Terminologi pentahapan pengolahan dan pengamatan data adalah sebagai berikut :

a. Kulit krom basah diketam

b. Diadakan pengamatan terhadap beratnya

c. Diadakan proses pembasahan kembali

d.Diadakan proses penetralan

e. Diadakan proses penyamakan ulang

f. Diadakan proses peminyakan g. Diadakan proses penyamakan ulang

h. Diadakan proses pengeringan dan lain sebagainya sehingga diperoleh kulit kras

i. Diadakan pengamatan terhadap :

luas kulit dalam kaki persegi

berat kulit dalam kilogram

kulit kras diuji sesuai SII No. 0038-73 : Mutu dan cara uji kulit kras domba/ kambing.

j. Diadakan proses pembasahan kembali.

\subsubsection{Pengamatan dan Pengukuran Luas, Berat dan Tebal.}

Pengamatan dilakukan di P.T. Budi Rapih Yogyakarta terhadap kulit domba dan kulit kambing krom basah. Pengamatan luas, berat dan tebal terhadap kulit kambing dan kulit jaket untuk domba dilakukan pada saat-saat setelah diketam, setelah jadi kulit kras dan setelah jadi kulit glase.

\subsubsection{Cara Pengambilan Contoh (Sampel)}

Agar contoh yang diambil dari populasi kulit domba dan atau kulit kambing dapat mewakili dan dapat dipertanggungjawabkan, maka jumlah contoh yang akan diambil menggunakan rumus :

\section{$\mathrm{n}=0,5 \sqrt{ }$ N. Sesuai ISO 2588-1975}

dimana :

$\mathrm{n}=$ jumlah kulit yang diteliti

$\mathrm{N}=$ jumlah pemotongan domba atau kambing yang ada di DIY.

\subsubsection{Pengamatan dan Pengumpulan Data.}

Data yang dikumpulkan dari hasil pengamatan terhadap kulit domba dan atau kambing tersebut meliputi :

a. Kadar air dalam prosen.

b. Luas kulit dalam kaki persegi.

c. Berat kulit dalam kilogram (satu angka dibelakang koma).

Pengamatan dikerjakan terhadap tiap lembar contoh berturut-turut sebagai berikut :

a. Kulit domba dan kambing krom basah harus memenuhi SII. 0067-84, Kulit Domba dan atau Kambing Krom Basah (Wet blue).

b. Kulit Kras Domba dan Kambing harus memenuhi SII. 0038-73, Kulit Kras Domba/Kambing.

c. Kulit Jaket Domba harus memenuhi SII. 0061-73, Kulit Sarung Tangan dan Jaket Domba/Kambing.

d. Kulit glas kambing harus memenuhi SII. 0065-74, Kulit glase kambing. 


\subsubsection{Analisa Data}

Hasil akhir yang akan diperoleh dari penelitian ini merupakan perbandingan dari ukuran tertentu dengan ukuran sesudah mengalami tahap proses selanjutnya. Ukuran-ukuran tersebut merupakan hasil perhitungan rata-rata dengan rumus statistik sebagai berikut :

Rata-rata $($ mean $)=X=n \sum$ i $\times 1 / n$

Dimana:

$\mathrm{X}=$ rata-rata

$\mathrm{n}=$ jumlah data

$\mathrm{i}=$ nomor kelompok data

Kemudian dihitung simpangan bakunya dengan rumus :

Simpangan baku (Standar deviasi $)=S d=\underline{\sqrt{\Sigma(X-\bar{X})^{2}}}$

n

Dimana :

$\mathrm{Sd}=$ simpangan baku $=$ standard deviasi

$\mathrm{X}=$ data suatu kelompok

$\overline{\mathrm{X}}=$ rata-rata data

$\mathrm{n}=$ jumlah data

Untuk mengetahui apakah penelitian dilakukan dengan baik atau tidak, dilakukan perhitungan kesalahan baku (Standard Error) dengan rumus :

$$
C V=\frac{S d}{\bar{X}} \times 100 \%
$$

dimana :

$\mathrm{CV}=$ kesalahan baku

$\mathrm{Sd}=$ simpanan baku

$\overline{\mathrm{X}}=$ rata-rata data

Apabila CV berkisar antara 15-20\% maka menunjukkan bahwa penelitian dikerjakan dengan baik.

\section{PELAKSANAAN PENELITIAN}

\subsection{PELAKSANAAN PENELITIAN :}

\subsubsection{Pengukuran Kulit di Pabrik}

Seperti telah ditulis dalam pendahuluan, bahwa untuk perhitungan konversi harus diambil contoh dengan jumlah minimum $0,5 \sqrt{ } \mathrm{N}$ dimana $\mathrm{N}$ adalah jumlah domba atau kambing yang dipotong. Dengan demikian, jumlah minimum contoh untuk :
domba $=0,5 \sqrt{67.464}=130$ lembar
kambing $=0,5 \sqrt{ } 88.324=148$ lembar

a. Pengukuran kulit domba

Dilaksanakan di P.T. Budi Makmur Yogyakarta sebanyak 150 lembar kulit krom basah dengan perincian sebagai berikut :

$$
\text { ukur } \begin{aligned}
80-50 & \text { lembar } \\
90-50 & \text { lembar } \\
100-50 & \text { lembar }
\end{aligned}
$$

b. Pengukuran kulit kambing

Dilaksanakan di P.T. Tjondro Purnomo Tjipto, sebanyak 152 lembar dengan perincian sebagai berikut :

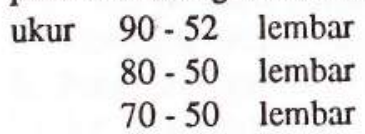

\subsubsection{Proses}

Jumlah kulit yang diproses :

A. kulit domba $=45$ lembar terdiri dari : 9 lb ukur 80 (masing-masing untuk 27 lb ukur 90 $3 \mathrm{x}$ ulangan) $\quad 9$ lb ukur 100

Proses kulit domba

1. Penyerutan dengan tebal $0,6 \mathrm{~mm}$

2. Penyamakan ulang
$200 \%$ air
$5 \%$ chromosal B - 60'

$0,9 \% \mathrm{Na}_{2} \mathrm{CO}_{3}$ masuk 3x @ 20' dilanjutkan sampai 120' Cuci

3. Penetralan $200 \%$ air

1,5\% $\mathrm{Na}_{2} \mathrm{CO}_{3}$ masuk 2x @ 15'dilanjutkan 60', test BCG penampang biru-netralisir cukup cuci bersih

4. Penyamakan ulang $200 \%$ air $60^{\circ} \mathrm{C}$

$5 \%$ Retanix HP - 60' ganti air

5. Penggemukan dan penyamakan ulang $200 \%$ air

$4 \%$ Lipoderm Liquor II

$4 \%$ Sandolix SP 60'

Vol. VII No. 12-13 1991/1992 
$4 \%$ Glufat 707

$3 \%$ Tanigan PAK $45^{\prime}$

$1 \% \mathrm{HCOOH} 20^{\prime}$

(pH $3,5-4)$

$0,5 \%$ Cortymol G

6. Pemeraman, pemerahan, pengeringan, pelembaban, peregangan, pementangan, pengeringan, perapihan kulit kras.

7. Pembasahan kembali :

$1000 \%$ air $60^{\circ} \mathrm{C}$

$0,5 \%$ Depan B $15^{\prime}$

$0,2 \%$ Amoniak 60 ,

Test organoleptis, cukup

cuci bersih

8. Cat dasar (dari berat basah)

$200 \%$ air $60^{\circ} \mathrm{C}$

$0,5 \%$ Amoniak $15^{\prime}$

$1 \%$ Derma Black 30'

9. Penggemukan (dari berat basah)
$3 \%$ Lipoderm Liquor II
$2 \%$ Glufat 707
$1 \% \mathrm{HCOOH}$
60
$0,5 \%$ Cortymol G
20 '

10. Pemeraman, pemerahan, pengeringan, pelembaban, peregang-an, pementangan, pengeringan.

11. Pengecatan tutup

45 lembar kulit 270 feet

pemakaian cat $30 \mathrm{ft} / 1 ; 9$ liter

$\mathrm{R} / 0,1 \mathrm{~kg} / \mathrm{l}$ Relcasyn Black

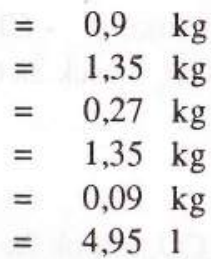

$0,03 \mathrm{~kg} / \mathrm{l}$ Relasyn PNE

$0,15 \mathrm{~kg} / \mathrm{l}$ R.E 384

$0,01 \mathrm{~kg} / \mathrm{l} \mathrm{T} . \mathrm{R} .0$

0,56 liter air

$=4,95$

Diulas $1 \mathrm{x}$ disemprot $2 \mathrm{x}$

12. Pengkilapan

Pemakaian $40 \mathrm{ft} / 1$

R/1 bag. L.E. 243

1 bag. L.E. 217

3 bag. super thiner

$=7 \quad 1$

$=1,4 \mathrm{~kg}$

$=1,4 \mathrm{~kg}$

semprot $2 x$

13. Hasil kulit jaket (domba) ini diukur tebal, berat dan luas.

Selanjutnya diuji dan hasil pengujian sesuai persyaratan SII. 0061-74, Kulit sarung tangan dan jaket domba/kambing.
B. Kulit kambing $=45$ lembar terdiri dari : $\quad 9 \mathrm{lb}$ ukur 70 (masing-masing untuk $27 \mathrm{lb}$ ukur 80 $3 \times$ ulangan)

$9 \mathrm{lb}$ ukur 90

Proses kulit kambing :

Bahan kulit kambing krom basah

1. Penyerutan dengan tebal $0,8 \mathrm{~mm}$

2. Penyamakan ulang

$200 \%$ air

$5 \%$ Chromosol B putar 60'

$0,9 \% \mathrm{NaHCO}_{3}$ masuk 3x @ 20' dilanjutkan 120'

3. Penetralan

$200 \%$ air

$1,5 \% \mathrm{NaHCO}_{3}$ masuk 3x@15' putar 60'

Test BCG - netral - cuci bersih

4. Penggemukan dan penyamakan ulang
$2 \%$ Glufat 707
$2 \%$ Sandolix
$60^{\prime}$
$200 \%$ air $80 \mathrm{C}$
$3 \%$ Tanigan PAK $45^{\prime}$
$0,5 \% \mathrm{HCOOH} 20^{\prime}, \mathrm{pH} 4$

Kulit diperam 1 malam kemudian diperah-keringkan kemudian dilembabkan dan terus diregangkan-pentang sampai kering menjadi kulit kras.

Kedua macam kulit kras tersebut (domba dan kambing) diukur tebal, berat dan luasnya. Selanjutnya diuji sesuai dengan SII Kulit kras 0038-73, Kulit kras domba/ kambing.

Bahan kulit kras kambing

Hasil uji pertama diproses menjadi kulit glase sebagai berikut :

1. Pembasahan kembali
$500 \%$ air
$0,5 \%$ Depan B $15^{\prime}$
$2 \%$ Amoniak 60'

Tes kebasahan, cukup teruskan dengan :

2. Pengecatan dasar
$200 \%$ air panas $60^{\circ} \mathrm{C}$
$0,5 \%$ amoniak $15^{\prime}$
$1 \%$ derma black $30^{\prime}$

3. Penggemukan kembali
$1,5 \%$ Lipoderm liquor II $60^{\circ}$
$1,5 \%$ Sandolix SP
$60^{\prime}$
$0,5 \% \mathrm{HCOOH}$
$0,5 \%$ Cortymol G

4. Pemeraman, pemerahan, pengeringan, pelembaban, peregangan, pemen- 
tangan, pengeringan.

5. Cat tutup
$0,1 \mathrm{~kg} / \mathrm{l}$ Relcasyn Black
$0,1 \mathrm{~kg} / 1$ Relcasyn M 50
$0,1 \mathrm{~kg} / \mathrm{l}$ R.E. 455
$0,03 \mathrm{~kg} / 1$ Relcasyn IMP

0,025 liter air

kulit diulas $1 \mathrm{x}$ keringkan dan disemprot $2 \mathrm{x}$

6. Pengkilapan

1. bag R.E. 443

1 bag R.E. 217

3 bag super thiner

7. Hasil kulit glase diukur tebal, luas dan beratnya. Selanjutnya kulit diuji.

\section{PEMBAHASAN}

\subsection{KULIT DOMBA}

1. Berat kulit mengalami penurunan antara $21-62 \%$. Hal ini karena pengetaman dan pengeringan.

2. Luas kulit mengalami penurunan setelah diketam $2 \%$, naik lagi setelah dipentang $3 \%$ dari luas semula.

3. Tebal kulit turun $31 \%$ sebelum disamak ulang, turun $28 \%$ setelah disamak ulang, dan turun $43 \%$ setelah jadi jaket dibanding dari tebal semula.

\subsection{KULIT KAMBING}

1. Berat kulit mengalami penurunan antara $19-63 \%$. Hal ini karena pengetaman dan pengeringan.

2. Luas kulit mengalami kenaikan $12 \%$ sebelum dilakukan perapihan, dan kenaikan tinggal $10 \%$ setelah dilakukan perapihan.

3. Tebal kulit mengalami penurunan setelah diketam, dan penurunan lebih kecil setelah dipentang.

Dari pembahasan tersebut dapat dibuat konversi dengan tahapan sebagai berikut :

I : Kulit krom basah

II : Kulit krom basah diketam

III : Kulit kras

IV : Kulit jaket/glase

\section{K E S I M P U L A N}

Dari hasil penelitian dapat disimpulkan hasil konversi sebagai berikut (hanya untuk DIY) :

TABEL KONVERSI KULIT DOMBA DARI KULIT KROM BASAH SAMPAI KULIT JAKET UNTUK KULIT UKUR 80 - 90 DAN 100

\begin{tabular}{|c|c|c|c|}
\hline Macam Konversi & & Kulit & domba \\
\hline 1. Lembar kulit krom basah I & kg kulit krom basah I & $1:$ & 0,60 \\
\hline 2. Lembar kulit krom basah I & $\mathrm{ft}^{2}$ kulit krom basah I & & 5,43 \\
\hline 3. kg kulit krom basah I & : $\mathrm{ft}^{2}$ kulit krom basah I & 1 & 9,19 \\
\hline 4. $\mathrm{ft}^{2}$ kulit krom basah I & : kg kulit krom basah I & 1 & 0,11 \\
\hline 5. Lembar kulit krom basah II & : kg kulit krom basah II & 1 & 0,49 \\
\hline 6. Lembar kulit krom basah II & : $\quad \mathrm{ft}^{2}$ kulit krom basah II & 1 & 5,38 \\
\hline 7. kg kulit krom basah II & : $\quad \mathrm{ft}^{2}$ kulit krom basah II & 1 & 11,53 \\
\hline 8. $\mathrm{ft}^{2}$ kulit krom basah II & : kg kulit krom basah II & 1 & 0,90 \\
\hline 9. Lembar kulit kras & : kg kulit kras & 1 & 0,23 \\
\hline 10. Lembar kulit kras & : $\mathrm{ft}^{2}$ kulit kras & 1 & 5,52 \\
\hline 11. kg kulit kras & : $\mathrm{ft}^{2}$ kulit kras & 1 & 24,30 \\
\hline 12. $\mathrm{ft}^{2}$ kulit kras & kg kulit kras & 1 & 0,04 \\
\hline 13. Lembar kulit jaket & : $\mathrm{kg}$ kulit jaket & 1 & 0,21 \\
\hline 14. Lembar kulit jaket & : $\mathrm{ft}^{2}$ kulit jaket & $1:$ & $\cdot 5,64$ \\
\hline 15. kg kulit jaket & : $\mathrm{ft}^{2}$ kulit jaket & $1:$ & 27,47 \\
\hline 16. $\mathrm{ft}^{2}$ kulit jaket & kg kulit jaket & $1:$ & 0,03 \\
\hline 17. kg kulit krom basah I & : kg kulit krom basah II & $1:$ & 0,81 \\
\hline 18. kg kulit krom basah I & : $\mathrm{ft}^{2}$ kulit krom basah II & $1:$ & 9,00 \\
\hline 19. $\mathrm{ft}^{2}$ kulit krom basah I & : kg kulit krom basah II & $1:$ & 0,09 \\
\hline 20. $\mathrm{ft}^{2}$ kulit krom basah I & : $\mathrm{ft}^{2}$ kulit krom basah II & $1:$ & 0,99 \\
\hline 21. kg kulit krom basah II & : kg kulit kras & $1:$ & 0,47 \\
\hline 22. kg kulit krom basah II & : $\mathrm{ft}^{2}$ kulit kras & $1:$ & 11,36 \\
\hline 23. ft ${ }^{2}$ kulit krom basah II & : $\mathrm{ft}^{2}$ kulit kras & $1:$ & 0,04 \\
\hline 24. $\mathrm{ft}^{2}$ kulit krom basah II & $\mathrm{ft}^{2}$ kulit kras & 1 & 1,02 \\
\hline 25. kg kulit krom & : kg kulit jaket & $1:$ & 0,91 \\
\hline 26. kg kulit kras & $: \mathrm{ft}^{2}$ kulit jaket & $1:$ & 24,84 \\
\hline 27. $\mathrm{ft}^{2}$ kulit kras & : kg kulit jaket & $1:$ & 0,04 \\
\hline 28. $\mathrm{ft}^{2}$ kulit kras & : $\mathrm{ft}^{2}$ kulit jaket & $1:$ & 1,02 \\
\hline 29. kg kulit krom basah I & : kg kulit kras & $1:$ & 0,34 \\
\hline 30. kg kulit krom basah I & : $\mathrm{ft}^{2}$ kulit kras & 1 & 9,23 \\
\hline 31. $\mathrm{ft}^{2}$ kulit krom basah I & : kg kulit kras & 1 & 0,04 \\
\hline 32. $\mathrm{ft}^{2}$ kulit krom basah I & : $\mathrm{ft}^{2}$ kulit kras & 1 & 1,02 \\
\hline 33. kg kulit krom basah I & : $\mathrm{kg}$ kulit jaket & 1 & 0,34 \\
\hline 34. kg kulit krom basah I & $\mathrm{ft}^{2}$ kulit jaket & 1 & 9,43 \\
\hline
\end{tabular}




\begin{tabular}{|c|c|c|c|c|}
\hline 5. $\mathrm{ft}^{2}$ kulit krom basah I & kg kulit jaket & 1 & : & 0,04 \\
\hline 6. $\mathrm{ft}^{2}$ kulit krom basah I & : $\mathrm{ft}^{2}$ kulit jaket & 1 & : & 1,04 \\
\hline 7. kg kulit krom basah II & : $\mathrm{kg}$ kulit jaket & 1 & : & 0,42 \\
\hline 8. kg kulit krom basah II & $: \mathrm{ft}^{2}$ kulit jaket & 1 & : & 11,60 \\
\hline 9. $\mathrm{ft}^{2}$ kulit krom basah II & : $\mathrm{kg}$ kulit jaket & 1 & : & 0,04 \\
\hline 0. $\mathrm{ft}^{2}$ kulit krom basah II & $: \mathrm{ft}^{2}$ kulit jaket & 1 & : & 1,05 \\
\hline
\end{tabular}

Keterangan :

$$
\begin{aligned}
& \mathrm{I}=\text { tidak diketam } \\
& \mathrm{ft}^{2}=\text { luas } \\
& \mathrm{II}=\text { diketam } \\
& \mathrm{kg}=\text { berat }
\end{aligned}
$$

Sedangkan untuk kulit kambing, hasil perhitungan/perbanding-an tidak nerupakan data konversi tetapi hanya merupakan angka-angka penlitian atau angka perbandingan karena jumlah contoh hanya 45 lembar, tidak memenuhi 0,5

TABEL ANGKA PERBANDINGAN KULIT KAMBING DARI KULIT KROM BASAH AMPAI KULIT GLASE UNTUK KULIT UKUR 70, 80 DAN 90

No. Macam Perbandingan

Kulit Kambing

1. Lembar kulit krom basah I

2. Lembar kulit krom basah I

3. $\mathrm{kg}$ kulit krom basah I

4. $\mathrm{ft}^{2}$ kulit krom basah I

5. Lembar kulit krom basah II

6. Lembar kulit krom basah II

7. kg kulit krom basah II

8. $\mathrm{ft}^{2}$ kulit krom basah II

9. Lembar kulit kras

10. Lembar kulit kras

1. kg kulit.kras

12. $\mathrm{ft}^{2}$ kulit kras

13. Lembar kulit glase

14. Lembar kulit glase

15. kg kulit jaket

16. $\mathrm{ft}^{2}$ kulit glase

17. kg kulit krom basah I

18. kg kulit krom basah I

19. $\mathrm{ft}^{2}$ kulit krom basah I

20. $\mathrm{ft}^{2}$ kulit krom basah I

21. kg kulit krom basah II

$\begin{array}{llllr}: & \text { kg kulit krom basah I } & 1 & : & 0,50 \\ : & \mathrm{ft}^{2} \text { kulit krom basah I } & 1 & : & 4,24 \\ \vdots & \mathrm{ft}^{2} \text { kulit krom basah I } & 1 & : & 8,50 \\ : & \text { kg kulit krom basah I } & 1 & : & 0,12 \\ \vdots & \text { kg kulit krom basah II } & 1 & : & 0,40 \\ \vdots & \mathrm{ft}^{2} \text { kulit krom basah II } & 1 & : & 4,32 \\ : & \mathrm{ft}^{2} \text { kulit krom basah II } & 1 & : & 10,75 \\ : & \text { kg kulit krom basah II } & 1 & : & 1,09 \\ : & \text { kg kulit kras } & 1 & : & 0,19 \\ : & \mathrm{ft}^{2} \text { kulit kras } & 1 & : & 4,75 \\ : & \mathrm{ft}^{2} \text { kulit kras } & 1 & : & 24,30 \\ : & \text { kg kulit kras } & 1 & : & 0,04 \\ : & \text { kg kulit glase } & 1 & : & 0,19 \\ : & \mathrm{ft}^{2} \text { kulit glase } & 1 & : & 4,75 \\ : & \mathrm{ft}^{2} \text { kulit glase } & 1 & : & 25,06 \\ : & \text { kg kulit glase } & 1 & : & 0,04 \\ : & \text { kg kulit krom basah II } & 1 & : & 0,19 \\ : & \mathrm{ft}^{2} \text { kulit krom basah II } & 1 & : & 4,66 \\ : & \text { kg kulit krom basah II } & 1 & : & 24,67 \\ : & \mathrm{ft}^{2} \text { kulit krom basah II } & 1 & : & 0,04 \\ : & \text { kg kulit kras } & 1 & : & 0,82\end{array}$

22. kg kulit krom basah II

23. $\mathrm{ft}^{2}$ kulit krom basah II

24. $\mathrm{ft}^{2}$ kulit krom basah II

25 . kg kulit kras

26. kg kulit kras

27. $\mathrm{ft}^{2}$ kulit kras

28. $\mathrm{ft}^{2}$ kulit kras

29 . kg kulit krom basah I

$30 . \mathrm{kg}$ kulit krom basah I

31. $\mathrm{ft}^{2}$ kulit krom basah I

32. $\mathrm{ft}^{2}$ kulit krom basah I

$33 . \mathrm{kg}$ kulit krom basah I

34. kg kulit krom basah I

35. $\mathrm{ft}^{2}$ kulit krom basah I

36. $\mathrm{ft}^{2}$ kulit krom basah I

$37 . \mathrm{kg}$ kulit krom basah II

$38 . \mathrm{kg}$ kulit krom basah II

39. $\mathrm{ft}^{2}$ kulit krom basah II

$40 . \mathrm{ft}^{2}$ kulit krom basah II $\mathrm{ft}^{2}$ kulit kras

$\mathrm{ft}^{2}$ kulit kras

$\mathrm{ft}^{2}$ kulit kras

$\mathrm{kg}$ kulit glase

$\mathrm{ft}^{2}$ kulit glase

$\mathrm{kg}$ kulit glase

$\mathrm{ft}^{2}$ kulit glase

kg kulit kras

$\mathrm{ft}^{2}$ kulit kras

kg kulit kras

$\mathrm{ft}^{2}$ kulit kras

$\mathrm{ft}^{2}$ kulit glase

kg kulit glase

$\mathrm{ft}^{2}$ kulit glase

kg kulit glase

$\mathrm{ft}^{2}$ kulit glase

kg kulit glase

$\mathrm{ft}^{2}$ kulit glase kg kulit glase

$\begin{array}{r}11,83 \\ 0,04 \\ 1,10 \\ 0,99 \\ 24,65 \\ 0,04 \\ 0,98 \\ 0,47 \\ 9,55 \\ 0,04 \\ 1,12 \\ 0,38 \\ 9,35 \\ 0,04 \\ 1,10 \\ 0,47 \\ 11,59 \\ 0,04 \\ 1,08 \\ \hline\end{array}$

Keterangan : 

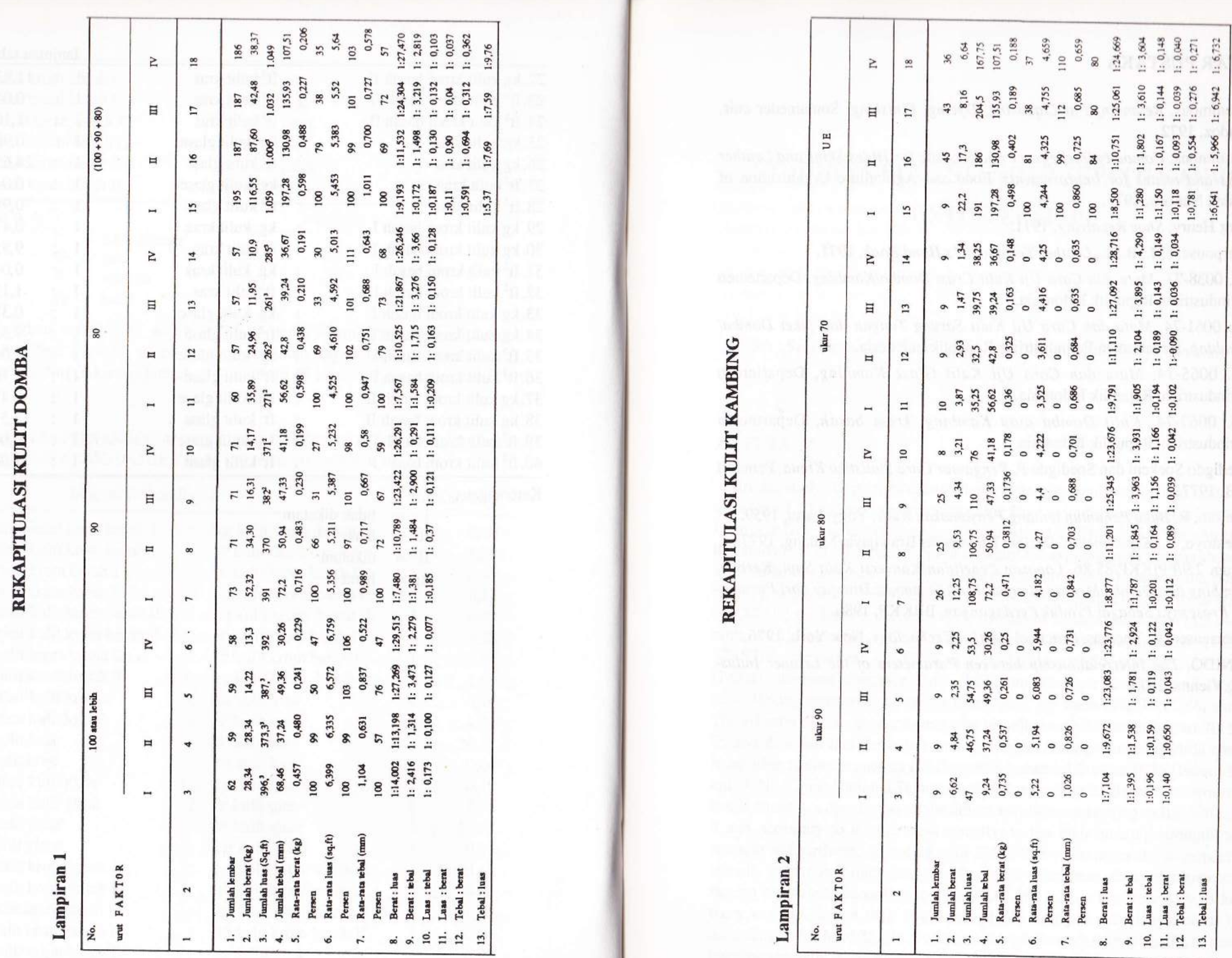


\section{DAFTAR PUSTAKA}

1. Anonimous, Retanning,Fat Liquoring, Dyeing, Finishing, Somaineder cuir, Sandoz, 1972.

2. Anonimous, Comodity Intellegence and Statistic for Hides Skins and Leather ways and means for Improvements, Food and Agriculture Organization of United Nations, 1975.

3. Karg Henry, Shoe Repairing, 1971.

4. Sharpouse, J.H., B.Sc., Leather Technician's Hand Book, 1971.

5. SII. 0038-73, Mutu dan Cara Uji Kulit Crust Domba/Kambing, Departemen Perindustrian, Republik Indonesia.

6. SII. 0061-74, Mutu dan Cara Uji Kulit Sarung Tangan dan jaket Dombal Kambing, Departemen Perindustrian, Republik Indonesia.

7. SII. 0065-74, Mutu dan Cara Uji Kulit Glase Kambing, Departemen Perindustrian, Republik Indonesia.

8. SII. 0067-74, Kulit Domba atau Kambing, krom basah, Departemen Perindustrian, Republik Indonesia.

9. Soedigdo Soekeni dan Soedigdo P, Pengantar Cara Statistika Kimia, Penerbit ITB, 1977.

10. Soejoto, R, Buku Penuntun tentang Penyamakan Kulit, Yogyakarta, 1959.

11. Soentoyo, Ir., Experimental Design, Universitas Brawijaya, Malang, 1977.

12. Team 2.9/PPIKKP/85-86, Laporan Penelitian Konversi Kulit Sapi, Kerbau, Kambing dan Domba Mentah Menjadi Kulit Tersamak Ditinjau dari Parameter Prosesnya Sebagai Produk Perdagangan, BBKKP, 1986.

13. Thorsensen, C. Thomas, Practical Leather Technology, New York, 1976.

14. UNIDO, The Interrelationship between Parameters of the Leather Industry, Vienna, 1973. 